\title{
Association between FTO variant and change in body weight and its interaction with dietary factors: the DiOGenes study
}

Article

Published Version

Online Open

Vimaleswaran, K. S., Ängquist, L., Hansen, R. D., van der A, D. L., Bouatia-Naji, N., Holst, C., Tjønneland, A., Overvad, K., Jakobsen, M. U., Boeing, H., Meidtner, K., Palli, D., Masala, G., Saris, W. H. M., Feskens, E. J. M., Wareham, N. J., Sørensen, T. I. A. and Loos, R. J. F. (2012) Association between FTO variant and change in body weight and its interaction with dietary factors: the DiOGenes study. Obesity, 20 (8). pp. 1669-1674. ISSN 1930-739X doi:

https://doi.org/10.1038/oby.2012.49 Available at https://centaur.reading.ac.uk/34652/

It is advisable to refer to the publisher's version if you intend to cite from the work. See Guidance on citing.

To link to this article DOI: http://dx.doi.org/10.1038/oby.2012.49

Publisher: Wiley

All outputs in CentAUR are protected by Intellectual Property Rights law, including copyright law. Copyright and IPR is retained by the creators or other copyright holders. Terms and conditions for use of this material are defined in the End User Agreement. 


\section{www.reading.ac.uk/centaur}

\section{CentAUR}

Central Archive at the University of Reading

Reading's research outputs online 


\title{
Association Between FTO Variant and Change in Body Weight and Its Interaction With Dietary Factors: The DiOGenes Study
}

\author{
Karani S. Vimaleswaran ${ }^{1}$, Lars Ängquist ${ }^{2}$, Rikke D. Hansen ${ }^{3}$, Daphne L. van der A ${ }^{4}$, \\ Nabila Bouatia- Naji ${ }^{1,5,6}$, Claus Holst ${ }^{2}$, Anne Tjønneland ${ }^{3}$, Kim Overvad $^{7,8}$, Marianne U. Jakobsen $^{8}$, \\ Heiner Boeing ${ }^{9}$, Karina Meidtner ${ }^{9}$, Domenico Palli ${ }^{10}$, Giovanna Masala ${ }^{10}$, Wim H.M. Saris ${ }^{11}$, \\ Edith J.M. Feskens ${ }^{12}$, Nicholas J. Wareham ${ }^{1}$, Thorkild I.A. Sørensen ${ }^{2}$ and Ruth J.F. Loos ${ }^{1}$
}

\begin{abstract}
Although FTO is an established obesity-susceptibility locus, it remains unknown whether it influences weight change in adult life and whether diet attenuates this association. Therefore, we investigated the association of FTO-rs9939609 with changes in weight and waist circumference (WC) during 6.8 years follow-up in a large-scale prospective study and examined whether these associations were modified by dietary energy percentage from fat, protein, carbohydrate, or glycemic index (GI). This study comprised data from five countries of European Prospective Investigation into Cancer and Nutrition (EPIC) and was designed as a case-cohort study for weight gain. Analyses included 11,091 individuals, of whom 5,584 were cases (age (SD), 47.6 (7.5) years), defined as those with the greatest unexplained annual weight gain during follow-up and 5,507 were noncases (48.0 (7.3) years), who were compared in our case-noncase (CNC) analyses. Furthermore, 6,566 individuals (47.9 (7.3) years) selected from the total sample (all noncases and 1,059 cases) formed the random subcohort (RSC), used for continuous trait analyses. Interactions were tested by including interaction terms in the models. In the RSC-analyses, FTO-rs9939609 was associated with BMI ( $\beta$ (SE), $0.17(0.08) \mathrm{kg} \cdot \mathrm{m}^{-2} /$ allele; $\left.P=0.034\right)$ and WC $(0.47(0.21) \mathrm{cm} /$ allele; $P=0.026)$ at baseline, but not with weight change (5.55 (12.5) g·year-1/allele; $P=0.66$ ) during follow up. In the CNC-analysis, FTO-rs9939609 was associated with increased risk of being a weight-gainer (OR: $1.1 ; P=0.045$ ). We observed no interaction between FTO-rs9939609 and dietary fat, protein and carbohydrate, and GI on BMI and WC at baseline or on change in weight and WC. FTO-rs9939609 is associated with BMI and WC at baseline, but association with weight gain is weak and only observed for extreme gain. Dietary factors did not influence the associations.
\end{abstract}

Obesity (2012) 20, 1669-1674. doi:10.1038/oby.2012.49

\section{INTRODUCTION}

Obesity, a risk factor for several common diseases, reflects an imbalance in energy intake and energy expenditure (1). Although environmental factors play an important role in the development of obesity, the heritability of BMI has been shown to be as high as $80 \%$ (2). Recent large-scale genomewide association studies have identified various genetic variants that are unequivocally associated with obesity-related traits (3-13). Of these loci, the genetic variation in FTO (fat mass and obesity associated) was the firstly discovered locus which has still the largest, yet small, effect on obesity susceptibility to date (3-6). Each FTO risk allele increases BMI by $0.26-0.66 \mathrm{~kg} \cdot \mathrm{m}^{-2}$, equivalent to $\sim 0.84-2.1 \mathrm{~kg}$ in body weight for a person of $1.80-\mathrm{m}$ tall, and the risk of obesity by $1.25-1.32$ odds (14).

Many studies $(15,16)$, although not all $(17,18)$, have shown that the BMI-increasing effect of the FTO variant is stronger in physically inactive individuals than in active individuals. It is however not known whether this attenuation is due to a healthy lifestyle in general, for example involving a particular

1MRC Epidemiology Unit, Institute of Metabolic Science, Cambridge, UK; ${ }^{2}$ Institute of Preventive Medicine, Copenhagen University Hospital, Copenhagen, Denmark; ${ }^{3}$ Danish Cancer Society Research Center, Unit of Diet, Genes and Environment, Copenhagen, Denmark; ${ }^{4}$ National Institute for Public Health and the Environment (RIVM), Bilthoven, The Netherlands; ${ }^{5}$ University Lille Nord de France, Lille, France; ${ }^{6} \mathrm{CNRS}$, UMR8199, Department of Genomics of Metabolic Diseases, Institut Pasteur de Lille, Lille, France; 'Department of Cardiology, Aalborg Hospital, Aarhus University Hospital, Aalborg, Denmark; ${ }^{8}$ Department of Clinical Epidemiology, Aarhus University Hospital, Aalborg, Denmark; ${ }^{9}$ Department of Epidemiology, GermanInstitute of Human Nutrition, Potsdam, Germany; ${ }^{10}$ Molecular and Nutritional Epidemiology Unit, Cancer Research and Prevention Institute (ISPO), Florence, Italy; ${ }^{11}$ Department of Human Biology, Nutrition and Toxicology Research Institute of Maastricht (NUTRIM), Maastricht, The Netherlands; ${ }^{12}$ Division of Human Nutrition, Wageningen University, Wageningen, The Netherlands. Correspondence: Ruth J.F. Loos (ruth.loos@mrc-epid.cam.ac.uk) 
dietary composition, or whether it is due to effects that are specific to physical activity.

In the present study, we examine the association of the FTOrs9939609 variant with BMI and WC at baseline and also change in weight and WC over an average period of 6.8 (SD 2.5) years. We furthermore test whether associations are modified by fat $\mathrm{E} \%$, carbohydrate $\mathrm{E} \%$, protein $\mathrm{E} \%$, and glycemic index (GI). We tested our hypotheses in a large prospective population which comprises data from five European countries $(n=$ 11,091) participating in the European Prospective Investigation into Cancer and Nutrition (EPIC).

\section{METHODS AND PROCEDURES Study population}

The study is part of the DiOGenes project (http://www.diogenes-eu. org/), a multidisciplinary European programme that focuses on dietary components and genetic and behavioural factors in the prevention of weight gain (19). The current analyses include data from five countries participating in the EPIC (19); i.e., Denmark (Aarhus and Copenhagen), Germany (Potsdam), United Kingdom (Norfolk), Italy (Florence), and the Netherlands (Doetinchem, Amsterdam, and Maastricht) (see Supplementary Table S1 online). Individuals younger than 60 years at baseline and younger than 65 years at follow-up, with stable smoking habits, without cancer, cardiovascular disease, or diabetes at baseline and at follow-up, and with an annual weight change not $>5 \mathrm{~kg} /$ year were eligible for the current study. In total, 50,293 men and women $(22,844$ participants from Denmark, 6,446 from the UK, 8,813 from Germany, 6,576 from the Netherlands, and 5,614 from Italy) for whom baseline information for BMI, weight, height, and diet, and follow-up information on weight were available, were eligible for inclusion in our analyses (see Supplementary Table S2 online).

\section{Study design}

The study design has been described in detail before (20). In brief, cases were defined as those individuals who had experienced the greatest degree of unexplained weight gain and were identified by using the residuals from a regression model of annual weight change on baseline values of age, weight, height, and smoking status (current/former/ nonsmokers) and follow-up time. In each of the countries except Italy, cases were identified as the 600 men and 600 women with the largest unexplained weight gain. As men were underrepresented (27\%) in the Italian cohort, 300 men and 900 women were selected to represent the sex distribution of this cohort.

Noncases together with some cases formed the random subcohort (RSC). The random sample subcohort comprised a random sample of individuals that was drawn in such a way that the total number of noncases (controls) in each centre equaled the number of cases $(n=1,200)$ (see Supplementary Table S2 online). To obtain in total 6,000 noncases, over sampling was performed in all centers except Denmark, where overlap between cases and subcohort was negligible $(n=79)$. In total, 7,063 participants were included in the RSC, of which 5,930 were noncases.

Of the 11,930 participants, 11,257 had DNA available for genotyping. Of these, genotyping failed for 143 samples and for 23 individuals, nutritional data was not available. Hence, our analyses included 11,091 individuals of whom, 5,584 were cases (weight-gainers) and 5,507 were noncases. For the case-noncase (CNC) analysis, 5,584 cases and 5,507 noncases were used. The RSC $(n=6,566)$ consisted of the 5,507 noncases (controls) and 1,059 cases.

\section{Anthropometry, dietary, and other measurements}

Details of the anthropometric measurements have been described previously (21). In brief, at baseline all participants were measured for weight, height, and waist circumference (WC) using standard study protocols. At follow-up, participants in Norfolk (UK) and Doetinchem
(NL) were measured by trained technicians, whereas participants of the other cohorts measured their weight and WC at home according to the guidance provided. The mean follow-up period was $6.8 \pm 2.5$ (mean \pm $\mathrm{SD})$ years.

Information on lifestyle was collected via self-administered questionnaires at baseline. Validated country-specific Food Frequency Questionnaires were used to collect dietary information at baseline (22). Energy and nutrient intake were calculated using country-specific food composition tables and subsequently calibrated using $24-\mathrm{h}$ recall data collected from a random sample of all EPIC participants (23). Energy and nutrient intake from 24-h recalls were calculated based on the standardized European Nutrient DataBase (24). The values of absolute intakes of fat, protein, and carbohydrate are transformed to energy-form by multiplying with macronutrient-specific factor, dividing by total energy, and finally multiplying by 100 in order to get values to percentage (0-100) form. This was used for calculating fat $\mathrm{E} \%$, protein $\mathrm{E} \%$, and carbohydrate $\mathrm{E} \%$. A specifically developed GI database was used to calculate dietary GI; the methodologies for their calculation have been described in detail elsewhere $(25,26)$.

\section{DNA extraction and genotyping}

Genomic DNA was extracted from the buffy coats with a salting out method for all participants except for samples from the UK for which whole-genome amplified DNA was used. The FTO variant (rs9939609) was genotyped using the Illumina Beadstation Genotyping System. Researchers and laboratory personnel were blinded to case status and phenotypic data of the samples. The concordance rate and reproducibility were $100 \%$ and genotyping call rate was $>98 \%$. Genotype distribution in the RSC was in accordance with Hardy-Weinberg equilibrium in each of the cohorts (see Supplementary Table S3 online).

\section{Statistical analysis}

The association between the FTO-rs9939609 variant and continuous traits (i.e., baseline BMI, baseline WC, weight change and change in WC) was examined in the RSC only, using linear regression analyses. The association between rs 9939609 and the risk of being a case (weight gainer) was tested using logistic regression comparing cases versus noncases. All association analyses assumed an additive effect of the minor allele and were adjusted for the baseline values of age, weight, and sex. The association analyses for weight gain were adjusted for age, sex, baseline weight and height. Weight gain was expressed in g/year.

Interactions between the SNP and the dietary factors (fat E\%, carbohydrate $\mathrm{E} \%$, protein $\mathrm{E} \%$, and GI) were tested by adding the interaction terms in the regression models. We also tested whether association and interaction were different across age and between men and women by including the respective interaction terms in the models.

As the genotype distribution of the variant rs9939609 $(P=0.012)$ (see Supplementary Table S3 online) and some phenotypic characteristics differed across the five countries, analyses were first conducted in each study center separately and subsequently meta-analyzed using a random effects model. This approach accounts for the possible heterogeneity across study centers and results in an overall (weighted) estimate. Heterogeneity was tested using the Cochran $Q$-test and $I^{2}$.

Statistical analysis was conducted using SAS 9.1 for windows (SAS Institute, Cary, NC) and STATA 9.2 for Windows (StataCorp LP, College Station, TX). Power calculations were performed using Quanto v1.1.1 (http://hydra.usc.edu/gxe). The statistical power to detect an effect size of $0.36 \mathrm{~kg} / \mathrm{m}^{2}$ as reported by Willer et al. (4) at a significance level of $5 \%$ was $99.99 \%$. At $80 \%$ power, we were able to detect an effect size of at least $0.18 \mathrm{~kg} / \mathrm{m}^{2}$ for a minor allele frequency of 0.41 and a sample size of 6,566 individuals. For gene-diet interactions, the least detectable effect sizes for annual weight gain and $\mathrm{CNC}$ status corresponding to $80 \%$ power and significance level 0.05 are $6.2 \mathrm{~g} /$ year and 1.012 odds per gene-diet unit respectively for carbohydrates (carbohydrates\%), $7.2 \mathrm{~g} /$ year, and 1.014 odds per gene-diet unit respectively for fat (fat $\%), 15.9 \mathrm{~g} / \mathrm{year}$, and 1.031 odds per gene-diet unit respectively for protein (protein $\%$ ) and $11.7 \mathrm{~g} /$ year and 1.023 odds per gene-diet unit respectively for GI (GI-unit). For ease 
of interpretation, an effect size of $6.2 \mathrm{~g} /$ year and 1.012 odds in a genediet interaction analysis means that the association between the FTO variant and weight gain is more pronounced in individuals with a higher carbohydrate energy percentage. More specifically, with every energy percentage increase in dietary carbohydrate, the association between the FTO variant and weight gain increases by $6.2 \mathrm{~g} /$ year and with the risk of being a weight-gainer increases by 1.012 odds.

\section{RESULTS}

The FTO-rs9939609 A-allele was associated with higher BMI ( $\beta$ (SE), $0.17(0.08) \mathrm{kg} \cdot \mathrm{m}^{-2} /$ allele; $\left.P=0.034\right)$ (Figure 1 ) and WC ( $\beta$ (SE), $0.47(0.21) \mathrm{cm} /$ allele; $P=0.026)$ in the RSC. Heterogeneity across the study centres was low to modest with effect sizes ranging from $-0.08 \mathrm{~kg} \cdot \mathrm{m}^{-2} /$ allele (in The Netherlands-Amsterdam \& Maastricht) to $0.43 \mathrm{~kg} \cdot \mathrm{m}^{-2} /$ allele (in Denmark) for BMI (heterogeneity $I^{2}=37.1 \%$ ) and from $-0.21 \mathrm{~cm} /$ allele (in The Netherlands-Amsterdam \& Maastricht) to $1.04 \mathrm{~cm} /$ allele (in Denmark) for WC $\left(I^{2}=37 \%\right)$.

In the analyses of the RSC, we observed no association between the FTO-rs9939609 variant and changes in weight ( $\beta$ (SE), 5.34 (12.5) g.year ${ }^{-1} /$ allele; $\left.P=0.66\right)$ or in WC ( $\beta$ (SE), $-0.004(0.02)$ $\mathrm{cm} \cdot$ year $^{-1} /$ allele; $\left.P=0.81\right)$. We observed no heterogeneity across study centres; the effect sizes ranged from $-18.01 \mathrm{~g} \cdot \mathrm{year}^{-1} / \mathrm{allele}$ (in The Netherlands-Amsterdam \& Maastricht) to 87.25 g.year ${ }^{-1}$ /allele (in The Netherlands-Doetinchem) for weight change (heterogeneity, $I^{2}=0.9 \%$ ) (Figure 2) and ranged from $-0.04 \mathrm{~cm} \cdot$ year $^{-1} /$ allele (in Italy-Florence) to $0.09 \mathrm{~cm} \cdot$ year $^{-1} /$ allele (in Denmark-Copenhagen and Aarhus) for change in WC.

The CNC comparison showed that the rs9939609 A-allele was associated with a 1.06-fold increased odds of being a weightgainer (95\% CI: 1.00-1.11; $P=0.045$ ) (Figure 3 ). The odds ratios across the study centres ranged from 1.01 (in Germany and Denmark) to 1.18 (in The Netherlands-Doetinchem) for weight change (heterogeneity, $I^{2}=0 \%$ ).

We observed no interactions between the rs9939609 variant and fat $\mathrm{E} \%$, protein $\mathrm{E} \%$, carbohydrate $\mathrm{E} \%$, or GI on any of BMI, WC, changes in weight or WC, and on risk of being a case (Table 1). Furthermore, there was no evidence for interaction of the variant with sex and age (sex: $P_{\text {interaction }}=0.65$; age: $\left.P_{\text {interaction }}=0.40\right)$ on BMI and WC at baseline and also change in weight and WC.

\section{DISCUSSION}

In this prospective study of 11,091 adults of five Europeans countries, we confirmed association of the FTO-rs9939609 variant with BMI and WC at baseline. However, no associations between this FTO variant and changes in weight or WC during 6.8 years of follow-up in adult life were observed. Furthermore, fat $\mathrm{E} \%$, carbohydrate $\mathrm{E} \%$, protein $\mathrm{E} \%$, and GI did not affect the associations of the FTO variant with baseline BMI, WC or with changes in weight or WC.

The overall effect of rs9939609 variant on BMI and WC is comparatively smaller in our study than the effect sizes shown in other studies, where each FTO risk allele has been shown to increase BMI by $\sim 0.40-0.66 \mathrm{~kg} \cdot \mathrm{m}^{-2}$ (4) and WC by $\sim 1.0-2.4 \mathrm{~cm}$ (27). When we stratified by study centre, the effect sizes in the present study ranged from $-0.08 \mathrm{~kg} \cdot \mathrm{m}^{-2} /$ allele to $0.43 \mathrm{~kg} \cdot \mathrm{m}^{-2} /$ allele for BMI and from $-0.21 \mathrm{~cm} /$ allele to $1.04 \mathrm{~cm} /$ allele for WC. Although our populations are not markedly different in terms of average BMI, age, or sex-ratio from those reported on in the past, even the upper range of effect sizes observed in the participating centres of our study only reached the lower range of those observed in previously published studies. It is not clear why we observed smaller average effect sizes, but this

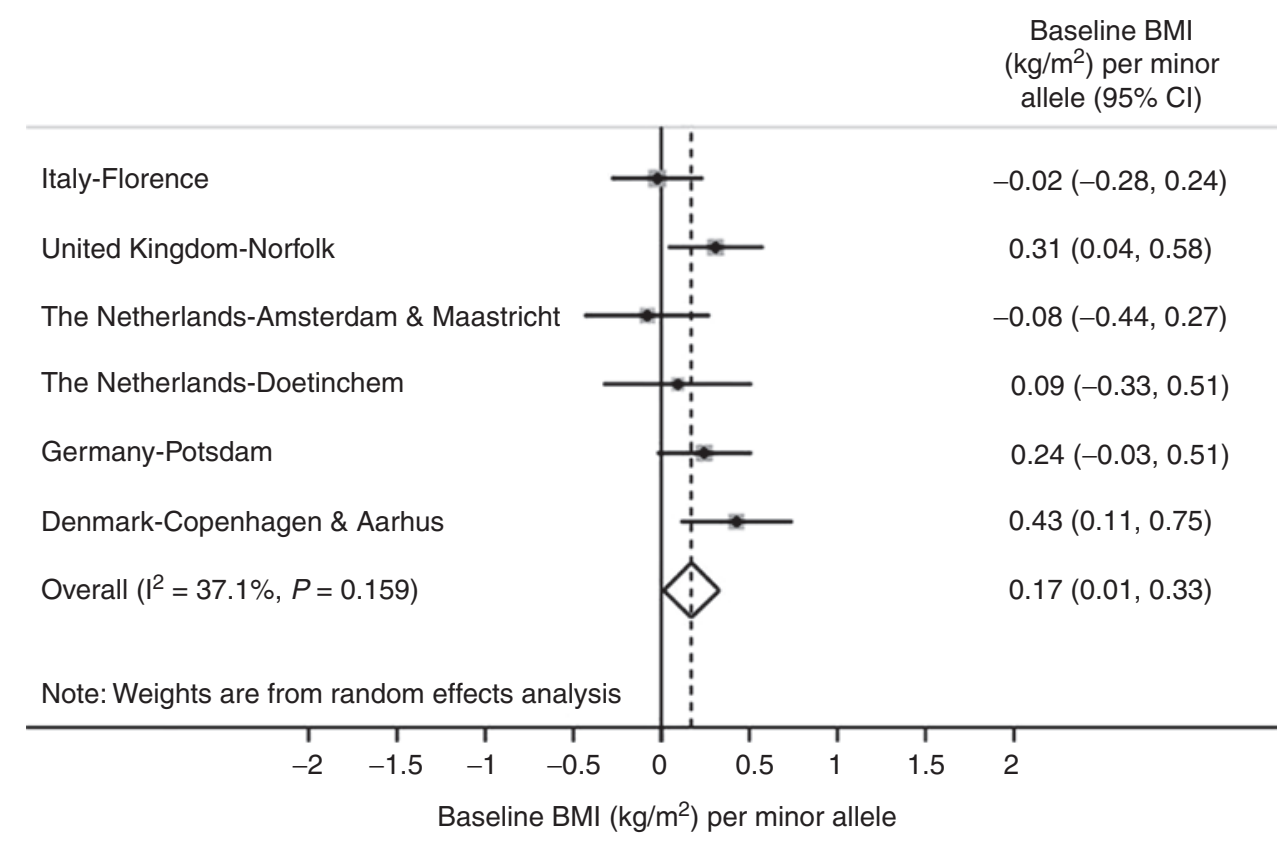

Figure 1 Association of the FTO variant, rs9939609, with baseline BMI $\left(\mathrm{kg} / \mathrm{m}^{2}\right)$ (random subcohort analysis) in the DiOGenes study. The analyses were first conducted in each study center and random-effect meta-analyses were used to pool the estimates and evaluate heterogeneity $(R) .95 \% \mathrm{Cl}$, $95 \%$ confidence interval. 


\section{GENETICS}

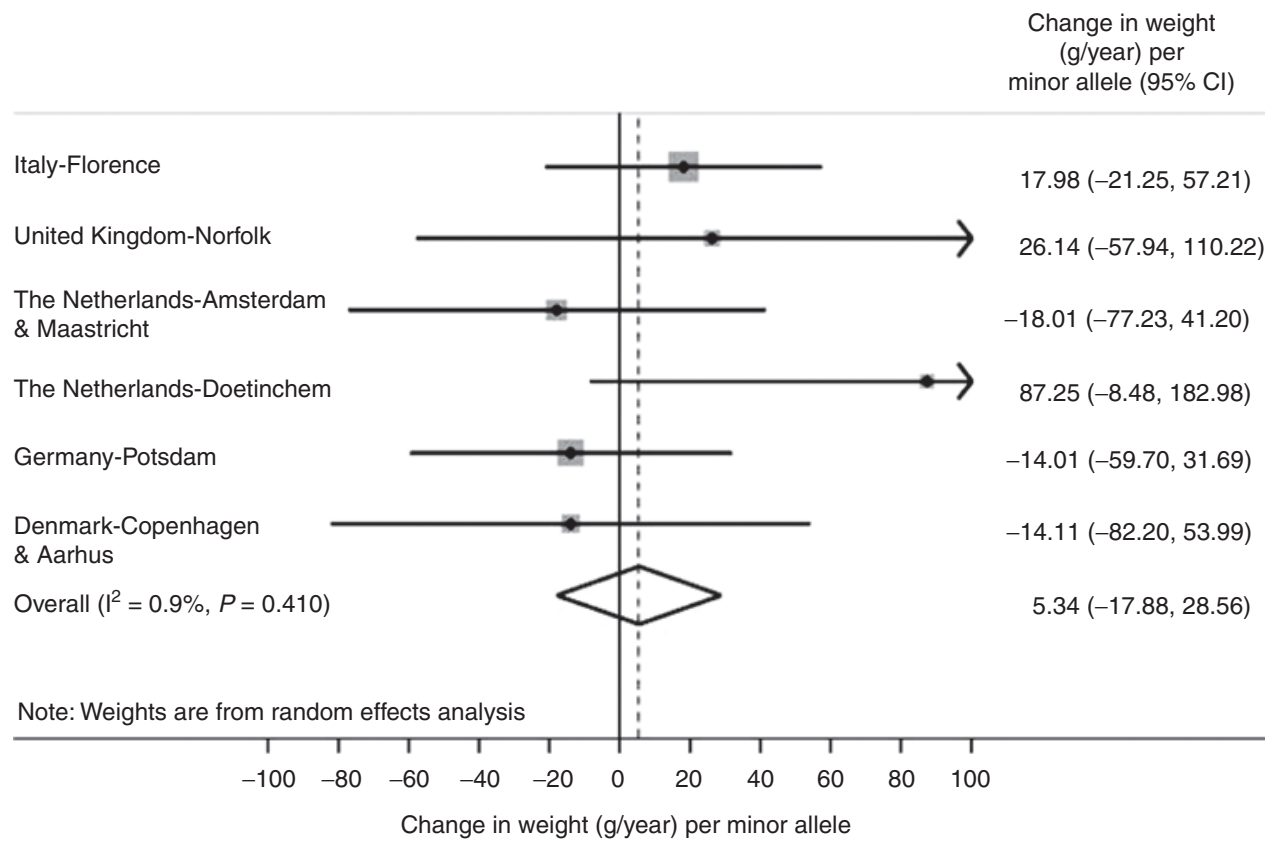

Figure 2 Association of the FTO variant, rs9939609, with weight change (g/year) (Random subcohort analysis) in the DiOGenes study. The analyses were first conducted in each study center and random-effect meta-analyses were used to pool the estimates and evaluate heterogeneity $(R) .95 \% \mathrm{Cl}$, $95 \%$ confidence interval.

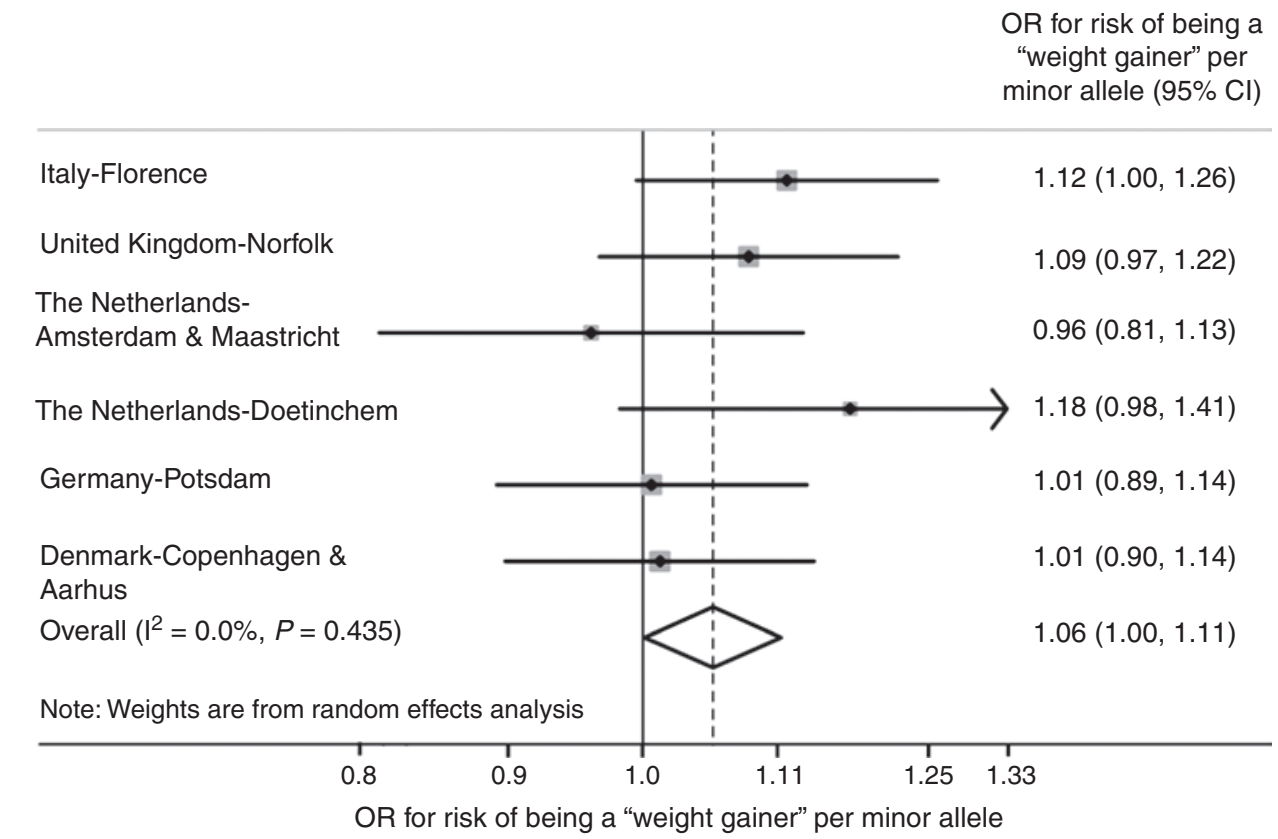

Figure 3 Association of the FTO variant, rs9939609, with risk of being a weight-gainer (case-noncase analysis) in the DiOGenes study. The analyses were first conducted in each study center and random-effect meta-analyses were used to pool the estimates and evaluate heterogeneity $(R) .95 \% \mathrm{Cl}$, $95 \%$ confidence interval.

is not necessarily affecting the chances of finding interactions between the gene variant and dietary factors.

Furthermore, we observed no association between the FTO variant and change in weight or in WC. However, we found a trend for the rs9939609 A-allele to be associated with 1.06fold increased odds of being a weight-gainer $(P=0.045)$, which suggests that FTO's effect on weight gain is only observed in extreme weight-gainers, at least in adults. Two recent studies showed that the FTO locus is associated with weight gain during childhood and adolescence, while the effect attenuates during adult life $(28,29)$. A case-cohort study in 1,629 Danish men, representing a broad range of BMI, showed that the AA genotype of the FTO variant, rs9939609, was significantly associated with weight gain from birth to the age of 
Table 1 Main effects and the interaction $P$ values for the FTO variant, rs9939609 in the random subcohort and case-noncase analyses of the study participants from the DiOGenes study

\begin{tabular}{|c|c|c|c|c|c|c|c|}
\hline & \multicolumn{2}{|c|}{ Main effects } & $\begin{array}{l}\text { Heterogeneity, } \\
\qquad I^{2}\end{array}$ & \multicolumn{4}{|c|}{ Interactions } \\
\hline \multicolumn{8}{|l|}{ Random subcohort analysis } \\
\hline Baseline BMI (kg·m²/allele) & $0.17 \pm 0.08$ & 0.034 & $37 \%$ & 0.88 & 0.45 & 0.70 & 0.52 \\
\hline Weight change (g·year ${ }^{-1} /$ allele) & $5.55 \pm 12.5$ & 0.66 & $8 \%$ & 0.10 & 0.82 & 0.37 & 0.99 \\
\hline Waist change (cm·year-1/allele) & $-0.004 \pm 0.02$ & 0.81 & $0 \%$ & 0.37 & 0.67 & 0.58 & 0.36 \\
\hline \multicolumn{8}{|l|}{ Case-noncase analysis } \\
\hline & $\begin{array}{l}\text { Odd ratio } \\
(95 \% \mathrm{Cl})\end{array}$ & $P$ value & $\begin{array}{l}\text { Heterogeneity, } \\
\qquad I^{2}\end{array}$ & $\begin{array}{c}P \text { value } \\
\text { for } F T O \times \\
\text { protein \% }\end{array}$ & $\begin{array}{l}P \text { value for } \\
F T O \times \text { fat } \%\end{array}$ & $\begin{array}{l}P \text { value for } F T O \times \\
\text { carbohydrate } \%\end{array}$ & $\begin{array}{l}P \text { value } \\
\text { for } F T O x \\
\text { glycemic } \\
\text { index }\end{array}$ \\
\hline
\end{tabular}

95\% Cl, 95\% confidence interval; WC, waist circumference.

7 years $(P=0.001)$ but was not associated with further weight gain during childhood and adolescence (28). A study in 1,240 men and 1,239 women from the MRC National Survey of Health and Development showed that the association between FTO variant, rs9939609, and BMI strengthened during childhood and adolescence, reached a peak strength at age 20 years, and then weakened during adulthood (29). Furthermore, two studies $(18,30)$, one in 1,275 Dutch adolescents and the other in 1,592 Europeans and African-Americans, failed to observe the changes in effect of the variant on adiposity measures across childhood and adolescence. These studies suggest that the difference in BMI and body weight between the three genotypes are established early in life and subsequently track into adulthood, which is consistent with our observations of a somewhat weaker association.

A few studies have examined the interaction between the FTO variant and dietary intake on obesity traits. A study in 204 German individuals found that the FTO-rs8050136 $\left(r^{2}=1.0\right.$, with the SNP rs9939609) was associated with BMI at baseline $(P<0.0001)$, but not with change in body weight after a 9-month lifestyle (exercise and dietary intervention) intervention programme ( $P=0.95$ for intervention vs. genotype effect) (31). Furthermore, a study in 776 individuals with a high cardiovascular risk observed no significant interaction between the nutritional intervention (followed-up for 3 years) and the FTO SNP rs9939609 on changes in the body weight (32). However, a cross-sectional study in 4,839 individuals from the population-based Malmö Diet and Cancer study (33) showed significant interactions between the FTO SNP rs 9939609 and fat $(P=0.04)$ and carbohydrate $(P=0.001)$ intakes on BMI. Also, a recent study in 21,675 healthy Caucasian women showed that lifestyle factors modified the genetic risk of FTO on obesity phenotypes among those who were both inactive and had high intake of calories (34). The lack of interaction in some of the studies could be due to the small sample size $(n<2,500)$ and short follow-up periods or inaccurate measurement of dietary information, which might reduce the statistical power to identify interactions. Despite the fact that our study is large and has sufficient power to identify small changes, we did not observe interaction between the $F T O$ variant and fat $\mathrm{E} \%$, protein $\mathrm{E} \%$, carbohydrate $\mathrm{E} \%$, and GI on weight change. While previous studies found that the BMI-increasing effect is modified by physical activity $(15,16,27)$, our study suggests that the composition of the food with regard to fat, protein, carbohydrate and GI does not have this effect. Our observations and those of others suggest that living a healthy lifestyle in general is not sufficient to attenuate the effect, but that the attenuation may be specific to physical activity.

A few studies have examined the influence of dietary factors on FTO gene function at the molecular level. The FTO variant $r 8050136\left(r^{2}=1.0\right.$, with the SNP rs9939609) affects binding affinity of the transcription factor, CUX1, which regulates the FTO gene expression (35). Reduced expression of Fto was shown to affect leptin signaling in vitro. Studies have also shown that excess fat intake (36) and high-protein diets (37) may influence the serum levels of leptin. It may be hypothesized that excess fat and protein intake might have an effect on the binding affinity of CUX1, which can affect FTO expression and, in turn, affect leptin signaling leading to obesity. However, further studies are required to prove this hypothesis.

In summary, our study confirms that genetic variation in FTO is associated with the general level of fatness as assessed by BMI and WC. However, the evidence of association with weight change during adult life is weak and association was only observed for more extreme weight gain. The results suggest that weight changes in adults are not influenced by interactions between the FTO polymorphism and macronutrient composition of the diet. 


\section{SUPPLEMENTARY MATERIAL}

Supplementary material is linked to the online version of the paper at http:// www.nature.com/oby

\section{ACKNOWLEDGMENTS}

The present study is supported by the DiOGenes project. DiOGenes is the acronym of the project "Diet, Obesity and Genes" supported by the European Community (Contract no. FOOD-CT-2005-513946). The parties of the project are listed on the website of the project (http:// www.diogenes-eu.org/). We thank the European Prospective Investigation on Cancer and Nutrition (The EPIC project: http://epic.iarc.fr/) for allowing access to the data.

\section{DISCLOSURE}

The authors declared no conflict of interest.

(C) 2012 The Obesity Society

\section{REFERENCES}

1. Bouchard $\mathrm{C}$. The magnitude of the energy imbalance in obesity is generally underestimated. Int J Obes (Lond) 2008;32:879-880.

2. Maes HH, Neale MC, Eaves LJ. Genetic and environmental factors in relative body weight and human adiposity. Behav Genet 1997;27:325-351.

3. Loos RJ, Lindgren CM, Li S et al.; Prostate, Lung, Colorectal, and Ovarian (PLCO) Cancer Screening Trial; KORA; Nurses' Health Study; Diabetes Genetics Initiative; SardiNIA Study; Wellcome Trust Case Control Consortium; FUSION. Common variants near MC4R are associated with fat mass, weight and risk of obesity. Nat Genet 2008;40:768-775.

4. Willer CJ, Speliotes EK, Loos RJ et al.; Wellcome Trust Case Control Consortium; Genetic Investigation of ANthropometric Traits Consortium. Six new loci associated with body mass index highlight a neuronal influence on body weight regulation. Nat Genet 2009;41:25-34.

5. Frayling TM, Timpson NJ, Weedon MN et al. A common variant in the FTO gene is associated with body mass index and predisposes to childhood and adult obesity. Science 2007;316:889-894

6. Scuteri A, Sanna S, Chen WM et al. Genome-wide association scan shows genetic variants in the FTO gene are associated with obesity-related traits. PLoS Genet 2007:3:e115.

7. Thorleifsson G, Walters GB, Gudbjartsson DF et al. Genome-wide association yields new sequence variants at seven loci that associate with measures of obesity. Nat Genet 2009;41:18-24.

8. Scherag A, Dina C, Hinney A et al. Two new Loci for body-weight regulation identified in a joint analysis of genome-wide association studies for earlyonset extreme obesity in French and german study groups. PLoS Genet 2010;6:e1000916.

9. Heard-Costa NL, Zillikens MC, Monda KL et al. NRXN3 is a novel locus for waist circumference: a genome-wide association study from the CHARGE Consortium. PLoS Genet 2009;5:e1000539.

10. Meyre D, Delplanque J, Chèvre JC et al. Genome-wide association study for early-onset and morbid adult obesity identifies three new risk loci in European populations. Nat Genet 2009;41:157-159.

11. Lindgren CM, Heid IM, Randall JC et al:; Wellcome Trust Case Control Consortium; Procardis Consortia; Giant Consortium. Genome-wide association scan meta-analysis identifies three Loci influencing adiposity and fat distribution. PLoS Genet 2009:5:e1000508.

12. Speliotes EK, Willer CJ, Berndt SI et al.; MAGIC; Procardis Consortium. Association analyses of 249,796 individuals reveal 18 new loci associated with body mass index. Nat Genet 2010;42:937-948.

13. Heid IM, Jackson AU, Randall JC et al.; MAGIC. Meta-analysis identifies 13 new loci associated with waist-hip ratio and reveals sexual dimorphism in the genetic basis of fat distribution. Nat Genet 2010;42:949-960.

14. Loos RJ. Recent progress in the genetics of common obesity. Br J Clin Pharmacol 2009:68:811-829

15. Andreasen $\mathrm{CH}$, Stender-Petersen $\mathrm{KL}$, Mogensen MS et al. Low physical activity accentuates the effect of the FTO rs9939609 polymorphism on body fat accumulation. Diabetes 2008:57:95-101.

16. Rampersaud E, Mitchell BD, Pollin Tl et al. Physical activity and the association of common FTO gene variants with body mass index and obesity. Arch Intern Med 2008;168:1791-1797.
17. Jonsson A, Renström F, Lyssenko $V$ et al. Assessing the effect of interaction between an FTO variant (rs9939609) and physical activity on obesity in 15,925 Swedish and 2,511 Finnish adults. Diabetologia 2009;52:1334-1338.

18. Liem ET, Vonk JM, Sauer PJ et al. Influence of common variants near INSIG2, in FTO, and near MC4R genes on overweight and the metabolic profile in adolescence: the TRAILS (TRacking Adolescents' Individual Lives Survey) Study. Am J Clin Nutr 2010;91:321-328.

19. Saris WH, Harper A. DiOGenes: a multidisciplinary offensive focused on the obesity epidemic. Obes Rev 2005;6:175-176.

20. Du H, Vimaleswaran KS, Angquist L et al. Genetic polymorphisms in the hypothalamic pathway in relation to subsequent weight change-the DiOGenes study. PLoS ONE 2011;6:e17436.

21. Rinaldi S, Key TJ, Peeters PH et al. Anthropometric measures, endogenous sex steroids and breast cancer risk in postmenopausal women: a study within the EPIC cohort. Int J Cancer 2006;118:2832-2839.

22. Riboli E, Hunt KJ, Slimani $\mathrm{N}$ et al. European Prospective Investigation into Cancer and Nutrition (EPIC): study populations and data collection. Public Health Nutr 2002;5:1113-1124

23. Ferrari P, Day NE, Boshuizen $\mathrm{HC}$ et al. The evaluation of the diet/disease relation in the EPIC study: considerations for the calibration and the disease models. Int J Epidemiol 2008:37:368-378.

24. Slimani N, Deharveng G, Unwin I et al. The EPIC nutrient database project (ENDB): a first attempt to standardize nutrient databases across the 10 European countries participating in the EPIC study. Eur J Clin Nutr 2007;61:1037-1056.

25. van Bakel MM, Slimani N, Feskens EJ et al. Methodological challenges in the application of the glycemic index in epidemiological studies using data from the European Prospective Investigation into Cancer and Nutrition. J Nutr 2009:139:568-575

26. Du H, van der A DL, van Bakel MM et al. Glycemic index and glycemic load in relation to food and nutrient intake and metabolic risk factors in a Dutch population. Am J Clin Nutr 2008;87:655-661.

27. Vimaleswaran KS, Li S, Zhao JH et al. Physical activity attenuates the body mass index-increasing influence of genetic variation in the FTO gene. Am J Clin Nutr 2009:90:425-428.

28. Jess T, Zimmermann E, Kring Sl et al. Impact on weight dynamics and general growth of the common FTO rs9939609: a longitudinal Danish cohort study. Int J Obes (Lond) 2008;32:1388-1394.

29. Hardy R, Wills AK, Wong A et al. Life course variations in the associations between FTO and MC4R gene variants and body size. Hum Mol Genet 2010:19:545-552.

30. Liu G, Zhu H, Dong Y, Podolsky RH, Treiber FA, Snieder H. Influence of common variants in FTO and near INSIG2 and MC4R on growth curves for adiposity in African- and European-American youth. Eur J Epidemiol 2011;26:463-473

31. Haupt A, Thamer C, Machann J et al. Impact of variation in the FTO gene on whole body fat distribution, ectopic fat, and weight loss. Obesity (Silver Spring) 2008:16:1969-1972.

32. Razquin C, Martinez JA, Martinez-Gonzalez MA et al. A 3-year intervention with a Mediterranean diet modified the association between the rs9939609 gene variant in $\mathrm{FTO}$ and body weight changes. Int J Obes (Lond) 2010;34:266-272.

33. Sonestedt E, Roos C, Gullberg B et al. Fat and carbohydrate intake modify the association between genetic variation in the FTO genotype and obesity. Am J Clin Nutr 2009:90:1418-1425.

34. Ahmad T, Lee IM, Paré G et al. Lifestyle interaction with fat mass and obesity-associated (FTO) genotype and risk of obesity in apparently healthy U.S. women. Diabetes Care 2011;34:675-680.

35. Stratigopoulos G, LeDuc CA, Cremona ML, Chung WK, Leibel RL. Cut-like homeobox 1 (CUX1) regulates expression of the fat mass and obesityassociated and retinitis pigmentosa GTPase regulator-interacting protein1 -like (RPGRIP1L) genes and coordinates leptin receptor signaling. J Biol Chem 2011;286:2155-2170.

36. Lagiou P, Signorello LB, Mantzoros CS et al. Hormonal, lifestyle, and dietary factors in relation to leptin among elderly men. Ann Nutr Metab 1999; 43:23-29.

37. Weigle DS, Breen PA, Matthys CC et al. A high-protein diet induces sustained reductions in appetite, ad libitum caloric intake, and body weight despite compensatory changes in diurnal plasma leptin and ghrelin concentrations. Am J Clin Nutr 2005;82:41-48. 